\title{
O Welfare State como política pública de auxílio ao Programa Nacional de Fortalecimento da Agricultura Familiar
}

\author{
Emerson Juliano Lucca ${ }^{1}$ \\ Daniel Claudy da Silveira ${ }^{2}$ \\ Silvio Cezar Arend $^{3}$
}

\begin{abstract}
Resumo: Este estudo teve como objetivo evidenciar as perspectivas em relação às definições, conceitos e origem das políticas públicas, às várias facetas do desenvolvimento e emergência do Welfare State, do Estado do Bem-Estar Social e do Programa Nacional de Fortalecimento da Agricultura Familiar (PRONAF), consolidando-se como uma política pública de auxílio à agricultura familiar da Região Sul, e, em especial, o COREDE Celeiro. Desta forma, esta política objetiva a promoção do desenvolvimento regional, assegurando o custeio da safra e de investimentos, tais como aumento da produção de alimentos, aumento do número de pessoas ocupadas no segmento rural familiar e geração de renda. O programa caracteriza-se como política pública distributiva do Estado, com o intuito de reduzir as desigualdades sociais e econômicas do território, na lógica do Welfare State. Para a realização da pesquisa, foram utilizados materiais bibliográficos correspondentes às definições de políticas públicas, Welfare State, e consulta a fontes secundárias no que tange às informações sobre PRONAF, incluindo coleta na base de dados de os Ministério de Desenvolvimento Agrário (MDA), Ministério da Agricultura, Pecuária e Abastecimento (MAPA) e Instituto Brasileiro de Geografia e Estatística (IBGE). Evidencia-se que a Região Sul do Brasil, em especial o Rio Grande do Sul, ocupa o primeiro lugar em termos de número de contratos e de valores disponibilizados nos últimos anos. Desta forma, esse programa vem se consolidando como uma política pública de grande valia para os produtores rurais que se utilizam desse benefício para custear sua produção e fazer investimentos.
\end{abstract}

Palavras-chave: Políticas Públicas. Welfare State. PRONAF.

Abstract: The purpose of this study was to highlight the perspectives regarding the definitions, concepts and origin of public policies, the various facets on the development and emergence of the Welfare State, and the National Program for Strengthening Family Agriculture (PRONAF), consolidating itself as a public policy of assistance to the family agriculture of the South Region, and especially COREDE Missões. In this way, this policy aims to promote regional development, ensuring crop costs and investments, such as increasing food production; increase in the number of people employed in the rural family segment and income generation. The program is characterized as a distributive public policy, with the aim of reducing the social and economic inequalities of the territory, in the logic of the Welfare State. In order to carry out the research, we used bibliographic material corresponding to the definitions of public policies, Welfare State and consultation with secondary sources regarding information about PRONAF, including collection in the database of the Ministry of Agrarian Development (MDA), Ministry of Agriculture, Livestock and Supply (MAPA) and the Brazilian Institute

1 Doutorando no Programa de Pós-Graduação em Desenvolvimento Regional da UNISC.

lucca.emerson@gmail.com

2 Doutor em Desenvolvimento Regional (UNISC). Professor do Departamento de Ciências Econômicas da UNISC. daniel.claudy@hotmail.com

${ }^{3}$ Doutor em Economia. Professor do Programa de Pós-Graduação em Desenvolvimento Regional PPGDR/UNISC. silvio@unisc.br

COLÓQUIO - Revista do Desenvolvimento Regional - Faccat - Taquara/RS - v. 16, n. 1, jan./jun. 2019 
of Geography and Statistics (IBGE). It is evident that the Southern Region of Brazil, especially Rio Grande do Sul, ranks first in terms of the number of contracts and values made available in recent years. In this way, this program has been consolidated as a public policy of great value for the rural producers who use this benefit to finance their production and make investments.

Keywords: Public Policy. Welfare State. PRONAF.

\section{Introdução}

Atualmente, a temática sobre o desenvolvimento, que em tempos não muito distantes esteve atrelada a questões puramente econômicas, envolvendo basicamente o crescimento das nações ou regiões, vem sendo abordada com um novo olhar. Ao contrário de ser entendido como sinônimo de crescimento econômico (ancorado basicamente no regime de acumulação capitalista), o desenvolvimento, principalmente a partir das décadas de 1970 e 1980, ganha um novo enfoque, por meio de uma abordagem qualitativa, ou seja, não estritamente ligada à lógica do capital ou do crescimento econômico. Neste arcabouço, novos conceitos vão emergindo, abordando questões como qualidade de vida, liberdade, capacidade, sustentabilidade, especificidades regionais, políticas públicas, objeto de estudo desta pesquisa, e eliminação das desigualdades regionais.

Para Souza (2006), as definições de políticas públicas guiam nosso olhar para o lócus onde os embates em torno de interesses, preferências e ideias se desenvolvem, isto é, os governos. Apesar de optar por abordagens diferentes, as definições de políticas públicas assumem, em geral, uma visão holística do tema, uma perspectiva de que o todo é mais importante do que a soma das partes, e que indivíduos, instituições, interações, ideologia e interesses contam, mesmo que existam diferenças sobre a importância relativa destes fatores.

Do ponto de vista teórico-conceitual, a política pública, em geral, é um campo multidisciplinar, e seu foco está nas explicações sobre a natureza da política pública e de seus processos. Por isso, uma teoria geral da política pública implica a busca de uma síntese das teorias construídas no campo da sociologia, da ciência política e da economia. As políticas públicas repercutem na economia e nas sociedades, daí porque qualquer teoria da 
política pública precisa também explicar as inter-relações entre Estado, política, economia e sociedade (SOUZA, 2006, p. 25).

Elucidar questões sobre a formulação de estratégias e as políticas públicas adotadas pelo governo, bem como as necessidades latentes que cada território apresenta, principalmente em relação à eliminação das desigualdades, são pontos a serem discutidos. No entanto, observou-se que as políticas voltadas para a atividade agrícola, que antes privilegiavam setores mais capitalizados e uma esfera produtiva de commodities voltadas ao mercado internacional, começam a ter um olhar diferenciado, oferecendo benefícios à agricultura familiar, especialmente no que diz respeito a crédito rural, seguro da produção, preços mínimos, etc.

Observando esta trajetória, podemos dizer que os programas direcionados ao meio rural passaram por transformações no cenário recente, perdendo em parte aquela visão exclusivamente setorializada, creditícia e elitizada. Mas ainda é preciso assinalar que os mecanismos de apoio, instrumentalizados através dos financiamentos, não resolvem todos os problemas criados, mas, sim, colaboram para o desenvolvimento da agricultura. Desta forma, pode-se considerar que as políticas públicas diferenciadas apresentaram avanços de grande envergadura na trajetória brasileira, embora seja um processo em construção e com muitas pendências a serem contornadas.

Embora se saliente que existam problemas e desafios no processo de criação e implementação das políticas diferenciadas para o meio rural, são indiscutíveis os avanços presentes nesta esfera de intervenção nas últimas duas décadas (DELGADO, 2001). Na década de 1990, surgiram alguns programas que se aproximam dessa perspectiva menos tradicional de intercessão, em que o público atingido são os agricultores tradicionalmente marginalizados pelas políticas convencionais. Entre os mecanismos de apoio implementados, podem ser citados o Plano Nacional de Reforma Agrária (PNRA), o Programa Nacional de Fortalecimento da Agricultura Familiar (PRONAF), o Programa de Geração de Emprego e Renda (PROGER-RURAL) e o Programa Especial de Crédito para a Reforma Agrária 
(PROCERA $)^{4}$. Além destas intervenções, ganhou importância no espaço rural a política de previdência rural.

De acordo com Mattei (2001), a mudança neste cenário começa a ocorrer com a instituição de políticas agrícolas específicas para os diversos tipos de produtores rurais. $\mathrm{Na}$ discussão que será apresentada neste artigo, o programa central é a criação do PRONAF, que é uma antiga reivindicação dos trabalhadores rurais e que aborda a necessidade da formulação e implementação de políticas de desenvolvimento rural específicas, que atendam às necessidades e auxiliem o segmento numericamente mais importante, mas também o mais fragilizado da agricultura no Brasil, seja em termos de capacidade técnica, seja de inserção nos mercados agropecuários.

Nesse contexto, o presente artigo se propõe a analisar a utilização do PRONAF como uma ferramenta de desenvolvimento rural voltado à agricultura familiar, a partir de sua consolidação como política de auxílio à produção agrícola, no estado do Rio Grande do Sul (RS) e em especial na região do COREDE Celeiro. A análise será baseada nos contratos e investimentos realizados no ano de 2012 nos municípios que compõem o COREDE Celeiro.

Para se ter uma visão mais clara, é essencial construir uma breve discussão sobre a origem das políticas públicas em termos mundiais e, também, no Brasil, além de elucidar alguns aspectos sobre o Welfare State - Estado de Bem-Estar Social -, e a tentativa de sua aplicação na sociedade brasileira através do PRONAF. Para isso, usou-se como metodologia a consulta de materiais bibliográficos, resgatando as principais teorias acerca do tema proposto, bem como uma consulta à fonte de dados secundários, nos ministérios afetos ao tema e no IBGE.

O texto está disposto em três seções. A primeira apresenta a origem das políticas públicas no Brasil e no mundo, com um breve resgate teórico. A segunda seção aborda o conceito do Welfare State como o Estado de Bem-Estar Social, e a terceira traz alguns

\footnotetext{
${ }^{4}$ No caso dos programas de crédito (PRONAF, PROGER-RURAL E PROCERA), é importante destacar que a situação diferenciada não está somente no público atingido, mas também nas condições do financiamento, já que as taxas de juros são menores, existe um período maior de carência, o prazo para a quitação pode ser prorrogado, e é comum a presença de 'rebate' para os agricultores menos capitalizados.
} 
apontamentos sobre a política pública brasileira em relação ao PRONAF e aos contratos e investimentos realizados nos municípios pertencentes ao COREDE Celeiro no ano de 2012.

\section{Políticas públicas: conceito e evolução}

Nesta seção, é apresentada a literatura acerca das políticas públicas nos contextos internacional e nacional, de modo a proporcionar uma visão geral das suas diferentes trajetórias ao longo dos anos. O conhecimento na área de políticas públicas perpassou por quatro grandes pensadores, com as suas respectivas teorias:

a) Harold Laswell (1936): introduziu a expressão policy analysis (análise de política pública) ainda nos anos de 1930, como forma de estabelecer o diálogo entre cientistas sociais, grupos de interesse e governo, oportunizando conciliar conhecimento científico/acadêmico com a produção empírica dos governos (SOUZA, 2006).

b) Herbert Simon (1957): apresentou e discutiu o conceito de racionalidade limitada dos decisores públicos, originadores da expressão de policy makers, em que considera que a limitação da racionalidade poderia ser minimizada pelo conhecimento racional. $\mathrm{O}$ autor supracitado destaca que a racionalidade dos decisores públicos é determinada por condições como assimetria de informações (imperfeitas ou incompletas), tempo para a tomada de decisão, autointeresse dos decisores, entre outros (SOUZA, 2006).

De acordo com Souza (2006), Simon ainda relata que a racionalidade pode ser maximizada até um ponto satisfatório pela criação de estruturas - conjunto de regras e incentivos - que enquadre o comportamento dos atores e modele esse comportamento na direção de resultados desejados pela coletividade, e não na busca de satisfação de interesses individuais.

c) Charles E. Lindblom (1959; 1979): questionou a ênfase do racionalismo de Laswell (1936) e Simon (1957), de modo a propor a incorporação de outras variáveis à formulação e à análise de políticas públicas. Os argumentos de Lindblom estavam ancorados nas relações de poder e na integração entre as diferentes fases do processo decisório, que, não necessariamente, teriam um fim ou um princípio. As políticas públicas precisariam 
incorporar outros elementos à sua formulação e à sua análise, muito além do pressuposto da racionalidade dos agentes, tais como o papel das eleições, das burocracias, dos partidos, dos grupos de pressão e de interesse (SOUZA, 2006).

d) David Easton (1965): adotou uma abordagem sistêmica à área do conhecimento de políticas públicas, relacionando os aspectos referentes à sua formulação, aos seus resultados e ao ambiente. "Segundo Easton, políticas públicas recebem inputs dos partidos, da mídia e dos grupos de interesse, que influenciam seus resultados e efeitos" (SOUZA, 2006, p. 23-24).

\begin{abstract}
Não existe uma única, nem melhor, definição sobre o que seja política pública. Mead (1995) a define como um campo dentro do estudo da política que analisa o governo à luz de grandes questões públicas, e Lynn (1980), como um conjunto de ações do governo que irão produzir efeitos específicos. Peters (1986) segue no mesmo riacho: política pública é a soma das atividades dos governos, que agem diretamente ou através de delegação, e que influenciam a vida dos cidadãos. Já Dye (1984) sintetiza a definição de política pública como 'o que o governo escolhe fazer ou não fazer'. A definição mais conhecida continua sendo a de Laswell, ou seja, decisões e análises sobre política pública implicam responder às seguintes questões: quem ganha o quê, por quê e que diferença faz (SOUZA, 2006, p. 24).
\end{abstract}

Por conseguinte, do ponto de vista teórico-conceitual, a política pública em geral e a política social em particular são campos multidisciplinares, e seu foco está nas explicações sobre a natureza da política pública e seus processos. No entendimento de Souza (2006), a teoria geral da política pública implica a busca de sínteses teóricas construídas no campo da sociologia, da ciência política e da economia.

As políticas públicas repercutem nos diferentes campos disciplinares de uma sociedade. Assim, qualquer teoria da política pública precisa também explicar as interrelações entre o Estado, a política, a economia e a sociedade. A razão pela qual pesquisadores de diversas áreas do conhecimento partilham um interesse comum na área de políticas públicas tem contribuído para avanços teóricos e empíricos acerca do tema (SOUZA, 2006).

Nessa mesma linha, Souza (2006, p. 26) resume política pública “[...] como o campo do conhecimento que busca, ao mesmo tempo, 'colocar o governo em ação' e/ou analisar essa ação (variável independente) e, quando necessário, propor mudanças no rumo ou curso dessas ações (variável dependente)". 
Deste modo, “[...] a formulação de políticas públicas constitui-se no estágio em que os governos democráticos traduzem seus propósitos e plataformas eleitorais em programas e ações que produzirão resultados ou mudanças no mundo real" (SOUZA, 2006, p. 26).

Se admitirmos que a política pública seja um campo holístico, isto é, uma área que situa diversas unidades em totalidades organizadas, isso tem duas implicações. A primeira é que, como referido acima, a área torna-se território de várias disciplinas, teorias e modelos analíticos. Assim, apesar de possuir suas próprias modelagens, teorias e métodos, a política pública, embora seja formalmente um ramo da ciência política, a ela não se resume, podendo também ser objeto analítico de outras áreas do conhecimento, inclusive da econometria, já bastante influente em uma das subáreas da política pública, a da avaliação, que também vem recebendo influência de técnicas quantitativas. A segunda é que o caráter holístico da área não significa que ela careça de coerência teórica e metodológica, mas sim que ela comporta vários "olhares". Por último, políticas públicas, após desenhadas e formuladas, desdobram-se em planos, programas, projetos, bases de dados ou sistema de informação e pesquisas. Quando postas em ação, são implementadas, ficando daí submetidas a sistemas de acompanhamento e avaliação (SOUZA, 2006, p. 26).

A partir desta abordagem teórica apresentada, em relação à trajetória da política pública, parte-se para a abordagem sobre policy analysis, com base nos estudos de Klaus Frey. O autor (2000) categoriza a política em sete dimensões principais, apresentadas no quadro 1:

\section{Quadro 1 - Dimensões Políticas}

\begin{tabular}{|l|l|}
\hline \multicolumn{1}{|c|}{ DIMENSÃO POLÍTICA } & \multicolumn{1}{c|}{ ARCABOUÇO TEÓRICO } \\
\hline Polity & $\begin{array}{l}\text { Institucional - refere-se à ordem do sistema político, jurídico e político- } \\
\text { administrativo. }\end{array}$ \\
\hline Politics & Processual - ligada ao processo político. \\
\hline Policy & $\begin{array}{l}\text { Conteúdos políticos concretos (material) - configuração de programas } \\
\text { políticos. }\end{array}$ \\
\hline Policy Makers & Tomada de decisão dos gestores públicos. \\
\hline Policy Communit & Relacionada à comunidade de especialistas em política. \\
\hline Policy Analysis & Focada na análise das políticas públicas. \\
\hline Agent-Setting & Desdobra-se sobre a definição de uma agenda política. \\
\hline
\end{tabular}

Fonte: Frey (2000).

Dentro da categorização evidenciada por Frey (2000), dar-se-á ênfase à dimensão da policy analysis. Tal dimensão aborda a análise de políticas públicas, estando ainda subdividida em a) policy networks; b) policy arena; c) policy cycle. Na dimensão da policy 
analysis, residem as formas de políticas públicas, de modo que, para o desenvolvimento deste estudo, será analisada a categoria policy arena, sendo usada, neste arcabouço, como referência a base conceitual de Theodor Lowi (1964; 1972). O autor discute conceitos que geram pontos convergentes e divergentes, conflitos, vetos e formas de consenso e de apoio, no que tange ao sistema político de uma sociedade. No total, são quatro formatos de políticas: políticas distributivas, políticas regulatórias, políticas redistributivas e políticas constitutivas (FREY, 2000; SOUZA, 2006).

A política referenciada para o desenvolvimento deste estudo será a política distributiva, que é representada por propósitos setoriais e pontuais - a análise do PRONAF. Essas políticas são geralmente financiadas pela sociedade, através do orçamento geral, em benefício de pequenos grupos em diferentes segmentos (geográfica, renda, social). Caracterizam-se por decisões tomadas pelo governo, apresentando um baixo grau de contradição no estabelecimento dos processos políticos - serviços e benefícios (SOUZA, 2006).

Conforme a classificação de Lowi $(1964 ; 1972)$, no que tange às políticas distributivas, a próxima seção irá resgatar e discutir o Welfare State como uma maneira de diminuir as desigualdades dentro de um determinado território, no caso o Brasil.

\section{Breve histórico das políticas públicas no Brasil - o Welfare State, estado de bem-estar social}

O surgimento das políticas públicas, segundo Offe (1981), deve-se, principalmente, ao Welfare State, conceituado por este autor como a "fórmula da paz", instituída entre as grandes potências democráticas e capitalistas após a Segunda Guerra Mundial. Entre os ingredientes que formavam essa "receita da paz" estavam a responsabilidade do estado em fornecer assistência e apoio para os cidadãos que se apresentassem em situação de risco econômico e social, bem como a elaboração de políticas públicas, no intuito de diminuir os conflitos de classe e contrabalancear a assimétrica relação de poder entre trabalho e capital. 
Nessa mesma linha, o Welfare State tem origem nos países capitalistas desenvolvidos, através da provisão de serviços sociais para cobrir as mais variadas formas de risco de vida individual e coletiva. É conceituado como um sistema que envolve responsabilidade estatal na garantia do bem-estar básico dos cidadãos, o que deveria ocorrer através da institucionalização de políticas sociais (ESPING-ANDERSEN, 1995).

Os economistas clássicos do século XIX preocupavam-se com o relacionamento entre capitalismo e bem-estar social. Defendiam o Estado liberal contra o estado que preservava privilégios absolutistas, o protecionismo mercantilista e a corrupção (ARRETCHE, 1996, p. $85)$.

A produção a respeito do Welfare State é bastante vasta, refletindo um amadurecimento em sua análise - de variáveis analíticas e indicadores. Entre as décadas de 1950 e 1960, a análise e emergência do Welfare State estava baseada em indicadores como do volume do gasto social, e, já a partir da década de 1980, indicadores como sua forma e natureza ganham relevância (ESPING-ANDERSEN, 1995).

\footnotetext{
Dentro de um contexto teórico, na literatura internacional, o 'Welfare State' e sua emergência podem ser atribuídos a duas causas principais. A primeira, de natureza econômica, retrata o fenômeno do 'Welfare State' como um resultado ou subproduto necessário das profundas transformações desencadeadas a partir do século XIX, sejam elas o fenômeno da industrialização e modernização das sociedades ou o advento do modo capitalista de produção. A segunda causa, de natureza política ou institucional: uma vez dadas determinadas condições econômicas, seja o surgimento dos programas de proteção social, suas formas de expansão ou ainda suas variações, têm como razão causal fatores relacionados à luta de classes, a distintas estruturas de poder político, ou a distintas estruturas estatais e institucionais (ARRETCHE, 1996, p. 5).
}

Arretche (1996) argumenta que os condicionantes do Welfare State ocorrem devido ao processo de industrialização e, também, como uma resposta às necessidades de acumulação e legitimação do regime de acumulação capitalista. Além disto, para ela, as razões do surgimento de programas sociais estão associadas aos problemas e possibilidades postos pelo processo de industrialização, ou seja, o Welfare State seria uma tentativa de compensação dos problemas causados por este processo excludente. 
De acordo com Offe (1981), o Welfare State trata-se de um fenômeno das sociedades capitalistas avançadas, e estas sociedades criam estruturalmente problemas endêmicos e necessidades não atendidas (ARRETCHE, 1996). De acordo com Arretche (1996, p. 7), “[...] a correlação entre as variáveis entre crescimento industrial e gastos sociais, se dá no sentido de que a primeira é condição necessária para a segunda" (a ausência de programas sociais é fruto de sociedades que não produzem excedente nacional suficiente para financiá-los). Desse modo, a industrialização apresenta impactos em sua estrutura social. Por outro lado, Souza (2001) usa argumentos de ordem político-institucional na emergência e desenvolvimento do Welfare State, que é resultado de uma ampliação progressiva de direitos dos civis aos políticos e dos políticos aos sociais (cidadania).

Os direitos civis estão relacionados aos direitos necessários à liberdade individual, o
que compreende inclusive direitos no campo das relações de trabalho. Os direitos
políticos representam a participação no exercício do poder político. E, os direitos
sociais relacionam a participação na riqueza socialmente produzida. O divórcio
entre eles era tão completo que é possível, sem distorcer os fatos históricos,
atribuir o período de formação da vida de cada um a um século diferente: os
direitos civis ao século XVIII; os políticos, ao XIX, e os sociais, ao XX. Nos tempos
atuais, há uma tendência à universalização entre civil, político e social (ARRETCHE,
1996, p. 34).

Conforme Arretche (1996), além disso, é resultado de um acordo entre capital e trabalho organizado dentro do capitalismo, pela desmercadorização da força de trabalho e pelas estruturas estatais e instituições políticas. Dessa forma, é o capitalismo o fator gerador de intervenções estatais.

Segundo lan Gough, o regime de acumulação capitalista estabelece um entrave para a expansão das políticas sociais. Ou seja, a expansão e a emergência do Welfare State são travadas pelas possibilidades postas pela acumulação e pela própria capacidade de financiamento dos programas sociais. Por outro lado, uma separação entre as esferas política e econômica poderia possibilitar uma margem de manobra em tomadas de decisão estatal.

Arretche (1996, p. 45) identifica quatro razões do brutal crescimento dos gastos sociais:

i) elevação dos custos relativos dos programas; 
ii) mudanças populacionais;

iii) ampliação dos serviços; e

iv) ampliação das necessidades sociais.

Welfare State, no contexto institucional, "[...] é resultado da capacidade de mobilização de poder da classe trabalhadora no interior de diferentes matrizes de poder. [...] A defesa das políticas sociais é o próprio processo de constituição da classe trabalhadora, onde os objetivos históricos de emancipação passam pela desmercadorização da força de trabalho" (ARRETCHE, 1996, p. 46). Neste sentido, Souza (1999) comenta que o processo redistributivo das desigualdades próprias do mercado constitui-se elemento fundamental na institucionalização do pleno emprego através de pressões dos movimentos operários. Há três regimes de Welfare State: regime social-democrata; regime conservador e regime liberal.

O Welfare State é também resultado de configurações históricas particulares de estruturas estatais e instituições políticas (SOUZA, 1999). O Estado tem função própria, é uma organização que busca exercer controle sobre determinado território, estabelecendo relações geopolíticas de comunicação, dominação e competição com os outros estados, e devendo manter a ordem interna. A formação do Estado é explicada por fatores de ordem externa e de ordem interna. Na história particular de cada país, podem ser encontradas as variáveis específicas de explicação de uma determinada forma de desenvolvimento dos sistemas de proteção social.

Sendo assim, existem três elementos centrais que dão suporte a essa análise (ARRETCHE, 1996, p. 58-60):

1) formação do Estado Nacional, em que se definem as capacidades estatais e o grau de autonomia do estado;

2) contexto institucional, processo de formulação e sustentação política que ocorre no interior de um contexto institucional; 
3) processos de policy feedback, nos quais as ideologias e os valores culturais influenciam o discurso político, sendo que estes também são influenciados pelas características das políticas existentes.

O 'Welfare State' teve origem basicamente nos países desenvolvidos, mais particularmente após as Revoluções Industriais, coordenadas pelo regime de acumulação capitalista. No entanto, a prática do mesmo se deu de forma mais intensa no período pós-guerra, ou seja, a partir da segunda metade do século XX. Há, de certa forma, um consenso de que o 'Welfare State' é um resultado da pressão do modelo capitalista de produção sobre a sociedade, acentuando as desigualdades (capital versus exploração de mão de obra). Assim, o Estado deve interceder e propor intervenções que atenuem tais desigualdades, pela prática do bem-estar social. Nos países em desenvolvimento tardio, no caso do Brasil, é ainda mais importante o desenvolvimento e emergência do 'Welfare State', pois é onde acontece a maior exploração da mão de obra pelo capital, que acentua as desigualdades e é altamente concentradora de renda e de oportunidades (SILVEIRA et al., 2015, p. 90).

Neste contexto, dentro das políticas públicas distributivas classificadas por Lowi (1964; 1972), é dada ênfase ao estudo e análise do PRONAF, com o objetivo de prover crédito agrícola e apoio institucional aos pequenos agricultores rurais. Assim, a próxima seção apresenta o Programa criado em 1996, pelo Decreto Presidencial no 1.946 de 28/06/96, com o intuito de subsidiar novas estratégias para globalizar e integrar o contexto agrícola ao sistema moderno de mercado.

\section{Programa Nacional de fortalecimento da agricultura familiar (PRONAF)}

O PRONAF foi instituído, no âmbito do Crédito Rural, pela Resolução no 2.191, de 24 de agosto de 1995, do Banco Central do Brasil (BACEN, 2009), através do Conselho Monetário Nacional (CMN), como política de apoio financeiro às atividades agropecuárias exploradas mediante emprego direto da força de trabalho do produtor e de sua família. Nesse sentido, o Decreto $n^{\circ}$ 1.946, de 28 de junho de 1996, criou o PRONAF com a finalidade de promover o desenvolvimento sustentável do segmento constituído pelos agricultores familiares, de modo a propiciar-lhes o aumento da capacidade produtiva, a geração de empregos e a melhoria de renda. 
O dispositivo legal estabelece como estratégia do PRONAF a parceria entre os governos municipais, estaduais e federal, a iniciativa privada e os agricultores familiares e suas organizações. A aplicação dos recursos do governo federal requer a adesão das parcerias citadas mediante normas operacionais do Programa e suas contrapartidas.

Dessa forma, as diretrizes que orientam o Programa visam, entre outras melhorias, à qualidade de vida, no segmento da agricultura familiar, através do desenvolvimento rural sustentado; ao aumento da capacidade produtiva; e à criação de novas oportunidades de emprego e renda, beneficiando os produtores rurais descapitalizados e com baixa produtividade. Também visam ao acesso a tecnologias adequadas à agricultura familiar, buscando seu aprimoramento, bem como ao aumento da produtividade do trabalho agrícola pelo crescimento profissional, protegendo o meio ambiente.

\subsection{Características e funcionamento do PRONAF: linhas, programas e grupos}

De acordo com o (extinto) Ministério de Desenvolvimento Agrário (MDA), o PRONAF financia projetos individuais ou coletivos que gerem renda aos agricultores familiares e assentados da reforma agrária. Para um agricultor entrar no programa, ele deve primeiro discutir o que será financiado, se o custeio da safra ou o investimento em máquinas e implementos agrícolas. Tomada esta decisão, o produtor rural deve procurar algum sindicato rural ou a Empresa de Assistência Técnica e Extensão Rural (EMATER) para obter sua Declaração de Aptidão ao PRONAF (DAP), que é emitida segundo a renda do produtor e o tipo de atividade, sendo direcionado para uma das linhas de crédito do programa.

Segundo MDA (2015), os recursos do PRONAF podem ser destinados para o custeio da safra ou da atividade agroindustrial, seja para investimento em máquinas, equipamentos ou infraestrutura. Anualmente, os programas do PRONAF destinam recursos para custeio e investimento, financiando aos agricultores familiares atividades produtivas rurais, infraestrutura, treinamento, geração e transferência de tecnologias, entre outros benefícios (MDA, 2015). 
Dentre as linhas de crédito do PRONAF, são listados a seguir, de acordo com MDA (2015), os grupos onde os produtores rurais podem se enquadrar e as condições de crédito de cada grupo:

A. PRONAF Custeio: destinado ao financiamento das atividades agropecuárias e de beneficiamento ou industrialização da produção. Este crédito é considerado de curto prazo, pois sua previsão de reembolso é de até dois anos para o custeio agrícola. As taxas de juros variam de $2 \%$ a $4 \%$ ao ano. Além disso, existe um redutor que contempla os beneficiários que pagam em dia, assim, se reduz a taxa que é efetivamente cobrada.

B. PRONAF Investimento: seu propósito é o financiamento da implantação, ampliação ou modernização da estrutura produtiva, seja na propriedade rural ou em áreas próximas. É um crédito de longo prazo, cujo prazo de reembolso vai até oito anos, com um prazo de carência de cinco anos. Sua taxa de juros é de $4 \%$ ao ano, e os agricultores podem contar com um bônus de adimplência de $1 \%$.

C. PRONAF Agroindústria: destinado ao financiamento dos investimentos em beneficiamento, processamento e comercialização de produtos agropecuários, artesanais, florestais; extrativismo e turismo rural.

(Continua)

D. PRONAF Agroecologia: financia investimentos em produtos agroecológicos ou orgânicos. Abrange também os custos com implantação e manutenção do projeto.

E. PRONAF Eco: financia investimentos em técnicas que visam diminuir o impacto ambiental da atividade agrícola.

F. PRONAF Floresta: financia investimentos em atividades extrativistas ecologicamente sustentáveis, manutenção de áreas de preservação ambiental.

G. PRONAF Semiárido: destinado ao financiamento dos agricultores que vivem na região semiárida do Nordeste.

H. PRONAF Mulher: destinado às propostas de crédito para as mulheres agricultoras.

I. PRONAF Jovem: destinado às propostas de crédito para os jovens agricultores.

J. PRONAF Custeio e Comercialização de Agroindústrias Familiares: para agricultores e suas cooperativas. Destinado ao custeio do beneficiamento e industrialização da produção agrícola.

L. PRONAF Cota-parte: financia o investimento para a integralização de cotaspartes de agricultores familiares filiados em cooperativas de produção. Também pode ser usado para aplicação em capital de giro, custeio ou investimento.

M. Microcrédito Rural: financia atividades agrícolas e não agrícolas dos agricultores de renda mais baixa. É exclusivo dos beneficiários do Programa Nacional de Crédito Fundiário (PNCF) e do Programa Nacional da Reforma Agrária (PNRA).

N. PRONAF Mais Alimentos: destinado a projetos de investimento da produção em apicultura, aquicultura, avicultura, bovinocultura de corte e de leite, caprinocultura, fruticultura, olericultura, ovinocultura, suinocultura, pesca e para a 
produção de açafrão, arroz, centeio, feijão, mandioca, milho, sorgo e trigo (MDA, 2015).

Os agricultores contemplados pelo PRONAF são divididos em grupos, de acordo com sua renda anual bruta familiar. Sendo assim, para conseguir acessar este programa, os agricultores devem comprovar seu enquadramento mediante apresentação da DAP ativa, em um dos seguintes grupos:

Grupo A: são beneficiários do grupo os agricultores familiares do Programa Nacional de Reforma Agrária (PNRA), ou beneficiários do Programa Nacional de Crédito Fundiário do Governo Federal (PNCF), que não foram contemplados pelos investimentos do Programa de Crédito Especial para a Reforma Agrária (PROCERA). Também se enquadram neste grupo as famílias reassentadas devido à construção de barragens hidrelétricas. A renda anual bruta dos agricultores deste grupo deve ser de no máximo $\mathrm{R} \$ 14$ mil.

Grupo B: estão neste grupo os produtores rurais que tenham renda familiar anual de até $\mathrm{R} \$ \mathbf{m i l}$, excluídos os benefícios sociais; tenham uma propriedade menor do que quatro módulos fiscais; esta renda deve vir da exploração agropecuária e não agropecuária do estabelecimento, e que tenham no máximo dois empregados.

(Continua)

Grupo $\mathbf{C}^{5}$ : são beneficiários deste grupo os trabalhadores que explorem a terra na condição de proprietário, arrendatário, posseiro, parceiro ou concessionário de programa de reforma agrária; sejam residentes no local ou área próxima; não tenham área superior a quatro módulos fiscais; mínimo de $80 \%$ da renda proveniente da exploração agropecuária e não agropecuária da terra; tenham renda anual bruta familiar entre $\mathrm{R} \$ 1,5$ mil e $\mathrm{R} \$ 10 \mathrm{mil}$; tenham trabalho familiar como predominante na propriedade; ser egresso do Grupo A.

Grupo D: os mesmos do Grupo C, porém considerando as famílias que tenham renda anual bruta entre $\mathrm{R} \$ 10 \mathrm{mil}$ e $\mathrm{R} \$ 30 \mathrm{mil}$. Além disso, as famílias deste grupo podem manter até dois empregados permanentes, admitindo, ainda, uso de terceiros quando for necessário.

Grupo E: famílias que utilizem eventualmente o trabalho temporário, podendo ter no máximo dois empregados permanentes; famílias que tenham renda anual bruta entre $\mathrm{R} \$ 40$ mil e $\mathrm{R} \$ 60$ mil, excluídos benefícios sociais; mínimo de $80 \%$ da renda anual proveniente da exploração agropecuária e não agropecuária da terra.

Grupo A/C: fazem parte deste grupo os trabalhadores provenientes do PNRA ou PNCF; que já tiveram um contrato no Grupo $A$; não tenham contraído financiamento de custeio, exceto para o Grupo A/C (MDA, 2015).

\footnotetext{
${ }^{5}$ Para os Grupos "C", "D" ou "E", além dos critérios específicos para cada grupo, a resolução estabelece como regra geral a necessidade do enquadramento como agricultores familiares e trabalhadores rurais que explorem parcela de terra na condição de proprietário, posseiro, arrendatário, parceiro ou concessionário do PNRA; residam na propriedade ou em local próximo; não disponham, a qualquer título, de área superior a quatro módulos fiscais, quantificados segundo a legislação em vigor.
} 
Além destes, podem se enquadrar nos grupos, exceto nos grupos $A$ e $A / C$, e que tenham renda bruta familiar de até $\mathrm{R} \$ 110 \mathrm{mil}$, nos últimos 12 meses anteriores à solicitação da DAP, excluídos os benefícios sociais, e que tenham até dois empregados: pescadores artesanais, extrativistas que se dediquem à extração ecologicamente sustentável, silvicultores que promovam o manejo sustentável, aquicultores, maricultores, piscicultores, comunidades quilombolas, comunidades indígenas e agricultores familiares que se dediquem à criação de animais silvestres.

Outros beneficiários do PRONAF são agricultores que tenham renda familiar bruta, nos 12 meses anteriores à solicitação da DAP, entre $\mathrm{R} \$ 5$ mil e $\mathrm{R} \$ 110$ mil, excluídos os benefícios sociais; que não tenham propriedade superior a quatro módulos fiscais; que obtenham pelo menos $70 \%$ de sua renda em atividades de exploração agropecuária e não agropecuária dentro de sua propriedade. Os agricultores que tinham a DAP relacionadas aos grupos $C$, D e E, e que tenham novos financiamentos, enquadrar-se-ão nestes últimos casos (MDA, 2015).

A seguir, a Tabela 1 mostra o percentual de contratos e de valores (investimentos) disponibilizados, em cada região do Brasil, no período de 2001 a 2012. Observa-se que, nos estados das regiões Norte e Sudeste, houve aumento tanto no percentual de número de contratos quanto no percentual de recursos captados.

Tabela 1 - Contratos e valores totais disponibilizados pelo PRONAF, participação percentual das regiões do Brasil, 2001 a 2012

\begin{tabular}{|r|r|r|r|r|r|r|r|r|r|r|}
\hline \multirow{2}{*}{ Ano } & \multicolumn{2}{|c|}{ Centro-oeste } & \multicolumn{2}{c|}{ Nordeste } & \multicolumn{2}{c|}{ Norte } & \multicolumn{2}{c|}{ Suldeste } & \multicolumn{2}{c|}{ Sul } \\
\cline { 2 - 10 } & Contrato & Valor & Contrato & Valor & Contrato & Valor & Contrato & Valor & Contrato & Valor \\
\hline 2001 & 4,63 & 11,00 & 20,86 & 11,08 & 2,44 & 3,16 & 12,65 & 16,64 & 59,42 & 58,12 \\
\hline 2002 & 3,84 & 8,94 & 23,46 & 11,91 & 3,07 & 4,26 & 11,31 & 15,15 & 58,32 & 59,74 \\
\hline 2003 & 5,27 & 8,87 & 28,95 & 13,78 & 4,06 & 6,12 & 14,81 & 20,37 & 46,92 & 50,86 \\
\hline 2004 & 4,17 & 8,15 & 39,98 & 16,53 & 4,30 & 6,40 & 13,74 & 18,69 & 37,80 & 50,23 \\
\hline 2005 & 2,62 & 7,23 & 59,84 & 24,75 & 2,36 & 5,39 & 11,41 & 19,73 & 23,78 & 42,90 \\
\hline 2006 & 2,17 & 5,98 & 60,20 & 26,01 & 3,86 & 7,85 & 11,67 & 19,41 & 22,11 & 40,75 \\
\hline 2007 & 2,95 & 6,13 & 49,87 & 20,26 & 5,25 & 6,67 & 13,41 & 21,51 & 28,51 & 45,43 \\
\hline 2008 & 3,17 & 5,54 & 40,42 & 13,57 & 4,85 & 4,66 & 16,50 & 21,86 & 35,07 & 54,37 \\
\hline 2009 & 3,16 & 6,81 & 37,74 & 12,33 & 5,99 & 7,11 & 16,01 & 23,07 & 37,10 & 50,68 \\
\hline 2010 & 3,35 & 7,03 & 40,56 & 12,77 & 5,96 & 7,10 & 16,82 & 24,30 & 33,29 & 48,77 \\
\hline 2011 & 3,32 & 6,99 & 42,27 & 12,65 & 4,90 & 6,13 & 16,20 & 23,01 & 33,37 & 51,19 \\
\hline 2012 & 1,64 & 2,38 & 13,73 & 5,56 & 8,20 & 10,15 & 32,30 & 35,90 & 45,75 & 48,37 \\
\hline
\end{tabular}


Fonte: Elaborado pelos autores a partir dos dados disponibilizados pelo Anuário Estatístico do Crédito Rural (vários anos) - Banco Central do Brasil (BACEN, 2015).

A Tabela 1 aqui expressa tem como intuito analisar duas regiões que obtiverem o maior número de contratos nos últimos anos. Sendo assim, o percentual de contratos do Sul era de 59,42\%, em 2001, e caiu para 45,75\% em 2012. Porém os agricultores da Região Sul continuam com maior representatividade, detendo, em 2012, 48,37\% dos valores disponibilizados. Tal acontecimento pode ser explicado pelo fato de essa região possuir agricultores familiares mais capitalizados. Cabe ressaltar, porém, que a Região Sul, quando comparada com as demais regiões, apresenta tendência decrescente, tanto no número de contratos quanto no volume financeiro captado, embora seja a região mais beneficiada pelo programa.

No caso da Região Nordeste, o que se observa é que, de 2001 a 2011, há elevação expressiva do percentual de contratos, que passa de 20,86\% para 42,27\%. Em 2006, os agricultores familiares nordestinos conseguiram o feito de ter a maior parcela de recursos captados: $26,01 \%$. Desde então, os números relativos a essa região apresentam decréscimo substancial. O elevado número de contratos efetuados e o baixo percentual de valores disponibilizados para o Nordeste podem ser explicados pelo fato de seus agricultores familiares serem relativamente menos capitalizados, sendo proprietários de estabelecimentos menores e não tão integrados ao mercado, quando comparados aos estabelecimentos familiares do Sul.

Figura 1 - Estados brasileiros com o maior volume de recursos contratados, via PRONAF no ano de 2012 em percentual (\%). 


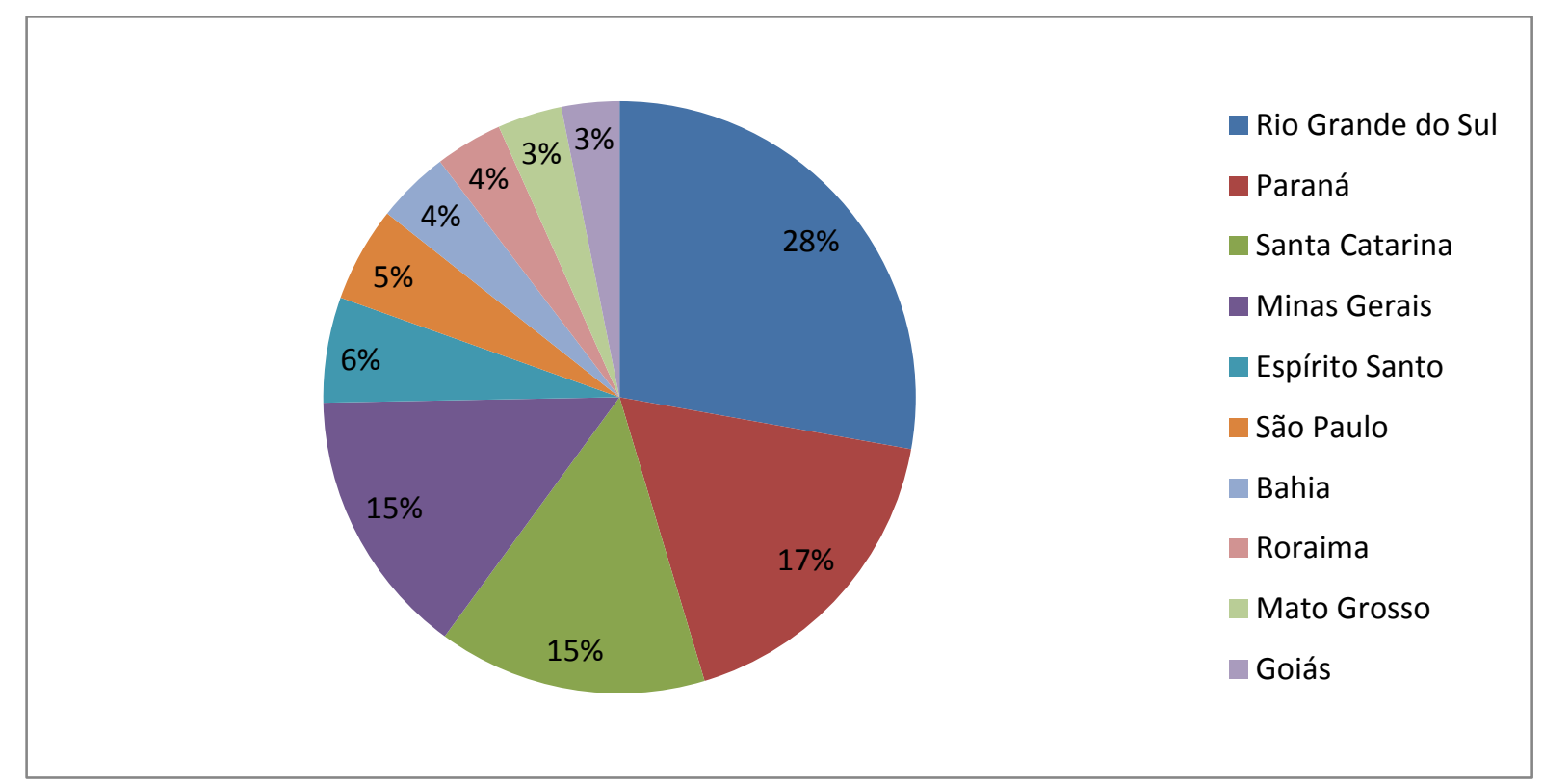

Fonte: Elaborado pelos autores a partir dos dados disponibilizados pelo Anuário Estatístico do Crédito Rural 2012 (BACEN, 2015).

A figura acima apresenta os dez estados com maior percentual de volume contratado via PRONAF. Estes estados concentram $80,93 \%$ do total aplicado, o que evidencia uma alta concentração em relação à distribuição de recursos do PRONAF entre os demais estados brasileiros. Outro ponto a ser destacado nesse quesito é que o estado do Rio Grande do Sul (RS) atingiu percentuais iguais aos dos estados da Região Nordeste somados.

Desde a implantação do PRONAF, no ano de 1996, a evolução dos recursos contratados por agricultores familiares do RS tem sido significativa. Em relação a todas as outras regiões, o estado vem liderando os contratos e investimentos realizados. Para essa análise, os valores foram inflacionados para o ano de 2012. Dessa forma, o valor contratado teve um aumento de 81,30\% de 1996 até 2012. Nessa comparação, o valor financeiro contratado passou de $R \$ 369$ milhões, em 1996, para $R \$ 3$ bilhões em 2012. Deste montante, $R$ \$ 1,4 bilhão foi para operações de investimento, e $R \$ 1,6$ bilhão, para operações de custeio.

A região analisada pertence ao COREDE Celeiro, a qual tem forte presença da agricultura familiar como setor produtivo, gerador de trabalho e renda. Sua participação no PRONAF, desde que este foi implantado no Brasil, merece o devido destaque. 
Desta forma, a Figura 2 representa o número de contratos realizados no ano de 2012 (último ano com informações oficiais disponíveis) nos municípios do COREDE Celeiro. O que se percebe entre os 21 municípios analisados é que os municípios de Crissiumal, Três Passos e São Martinho foram os que mais oficializaram contratos naquele ano. Isto se dá devido ao predomínio de um grande número de famílias rurais, pela existência de uma área de produção que permite que os investimentos sejam promissores e por serem municípios capitalizados e com diversidades de culturas predominantes.

Figura 2 - Relação total de contratos por município Região do COREDE Celeiro no ano de 2012

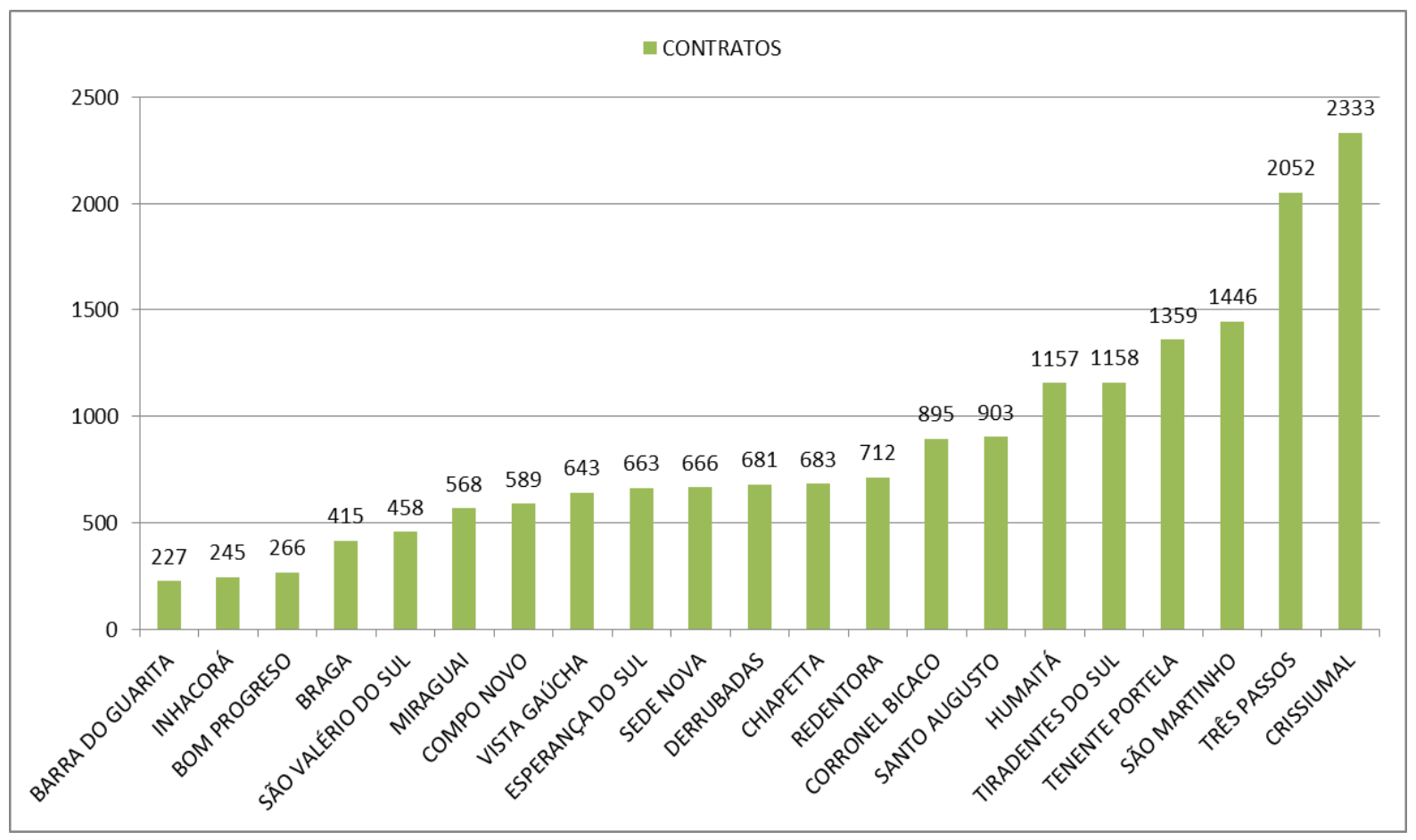

Fonte: Elaborado pelos autores a partir dos dados disponibilizados pelo Anuário Estatístico do Crédito Rural 2012 (BACEN, 2015).

A concentração de recursos do PRONAF, no Sul do Brasil, em especial na região Celeiro, evidencia a força da agricultura familiar. A grande concentração de recursos nos municípios pertencentes ao COREDE Celeiro reforça a importância do PRONAF, ao oportunizar, via financiamentos, possibilidades concretas de contribuição na melhoria das condições de vida e de trabalho, em investimentos na produção e no fortalecimento e desenvolvimento da agricultura familiar. 


\section{Figura 3 - Relação total de investimento por município Região do COREDE Celeiro no ano} de 2012

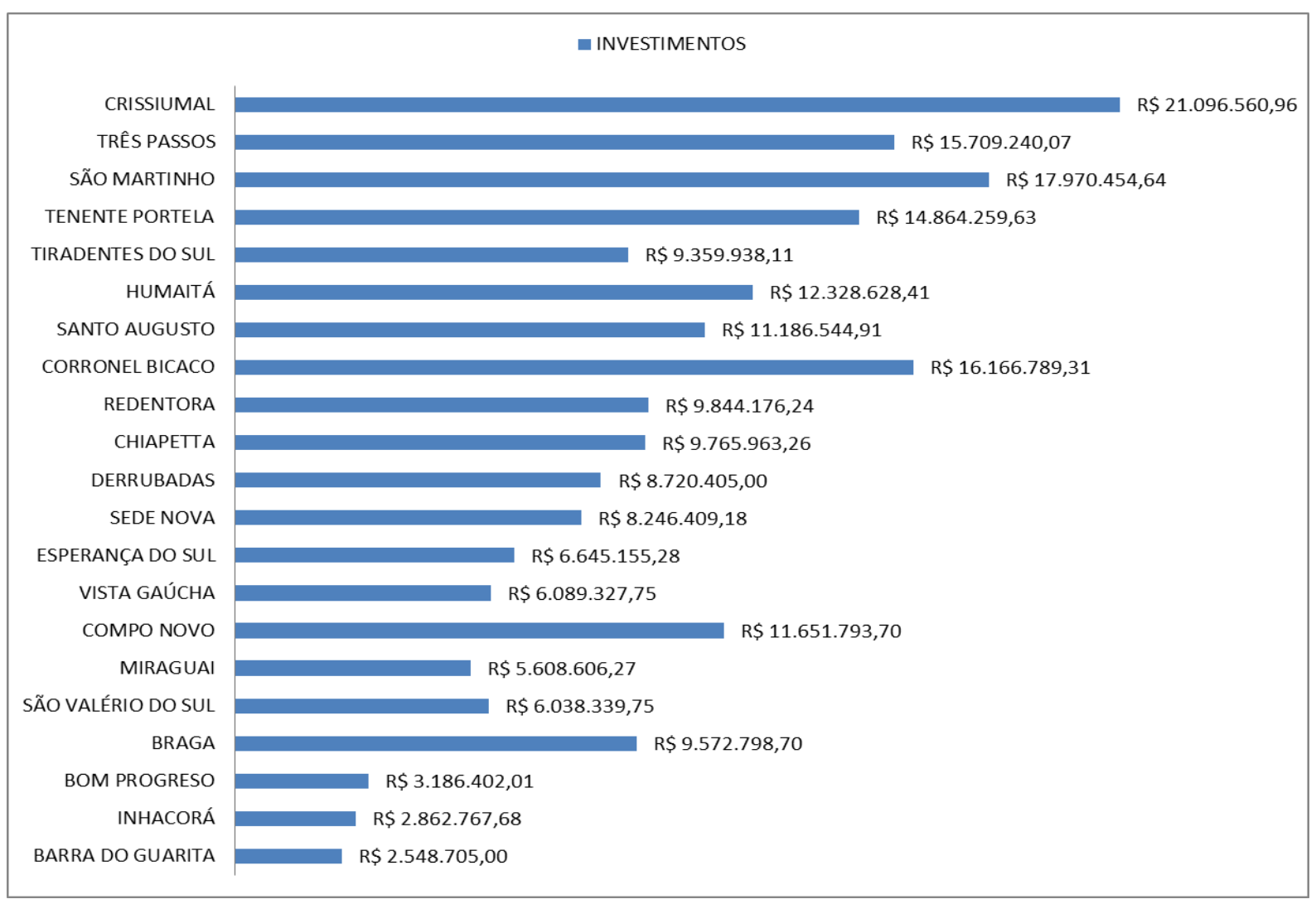

Fonte: Elaborado pelos autores a partir dos dados disponibilizados pelo Anuário Estatístico do Crédito Rural 2012 BACEN, 2015).

A Figura 3 evidencia os valores investidos pelos produtores rurais na região do COREDE Celeiro, que têm como objetivo fortalecer atividades do agricultor familiar, integrálo à cadeia do agronegócio, aumentar sua renda, melhorar o uso da mão de obra familiar e agregar valor ao produto e à propriedade. Dentre os municípios que mais usaram esse recurso, encontram-se na liderança os municípios de Crissiumal, São Martinho, Coronel Bicaco e Três Passos.

\section{Considerações finais}

O estudo apresentou um resgate teórico das políticas públicas que emanam da sociedade e o conceito de Welfare State, como Estado do Bem-Estar Social e suas razões de 
desenvolvimento e emergência nas sociedades capitalistas. Além disso, demonstrou uma análise do PRONAF, enquanto política pública de desenvolvimento social e econômico no Brasil.

Nesta perspectiva, o PRONAF passa a ser protagonista de uma política específica de fortalecimento e desenvolvimento, via financiamento das atividades produtivas do meio rural, e pode ser considerado como um marco em relação às políticas agrícolas anteriores, as quais não incluíam e não possibilitavam o avanço da agricultura familiar em diferentes regiões brasileiras (CARNEIRO, 1997).

Com efeito, observou-se que reduzir as desigualdades sociais e regionais no Brasil continua sendo o grande desafio; entretanto, o desenvolvimento necessita ser compreendido de forma distinta do mero crescimento/determinismo econômico, à medida que os objetivos do desenvolvimento vão além da mera multiplicação da riqueza material, inserida no contexto capitalista de produção, excludente e exploratório. Desse modo, o Welfare State surge como alternativa de intervenção do Estado para reduzir as desigualdades acentuadas pelo modelo capitalista de produção. Instituições tanto públicas quanto privadas (ou seja, a interação entre elas), são essencialmente importantes para o desenvolvimento regional, na intervenção efetiva na redução das desigualdades, tanto em relação à renda quanto em relação ao cunho social das propriedades rurais.

Dessa forma, as constantes reformulações sofridas por esse programa, segundo Mattei (2001; 2005), reforçam o quanto é necessário articular políticas públicas para a construção de um padrão de desenvolvimento sustentável, do qual os agricultores(as) familiares e suas famílias consigam usufruir, de forma a aumentar e diversificar a produção, com o consequente crescimento dos níveis de emprego e renda, proporcionando-lhes bemestar social e qualidade de vida.

O PRONAF como política pública de concessão de crédito rural pode ser considerado um mecanismo importante para o desenvolvimento das atividades produtivas do segmento rural familiar. A expressiva adesão ao Programa pelos agricultores familiares da região Celeiro sinaliza a real necessidade e a importância de políticas públicas específicas para o fortalecimento da agricultura familiar. 
Por fim, o PRONAF é um instrumento diferenciado, pois permite o fortalecimento do segmento agrícola familiar e possibilita condições para o desenvolvimento sustentável da agricultura. Desta forma, as análises aqui apresentadas revigoram a contribuição do programa, fortalecendo o desenvolvimento regional e atenuando as desigualdades sociais e econômicas pelas quais os produtores rurais passam.

\section{Referências}

ARRETCHE, Marta. T. S. Emergência e desenvolvimento do Welfare State: teorias explicativas. BIB, São Paulo, 1996. Disponível em: <file://C:/Documents\%20and\%20Settings/USER/ eus\%20documentos/Downloads/bib39_1.pdf>. Acesso em: 15 jul. 2015.

BACEN. Banco Central do Brasil. Manual de Crédito Rural. 2009. Disponível em:

$<$ http://www4.bcb.gov.br/NXT/gateway.dll?f=templates\&fn=default.htm\&vid=nmsGeropMC R:idvGeropMCR>. Acesso em: 15 jul. 2015.

CARNEIRO, Maria José. Política pública e agricultura familiar: uma leitura do Pronaf. Estudos Sociedade e Agricultura, n. 8, p. 70-82, abr. 1997.

DELGADO, N. G. Política econômica, ajuste externo e agricultura. In: Leite, S. P. (Org.). Políticas públicas e agricultura no Brasil. Porto Alegre: UFRGS, 2001. p. 15- 52.

DYE, Thomas D. Understanding Public Policy. Englewood Cliffs: Prentice- Hall, 1984.

ESPING-ANDERSEN, G. As Três Economias Políticas do Welfare State. Lua Nova, São Paulo, v. 24, p. 85-116, 1995. Disponível em: <http://www.scielo.br/pdf/ln/n24/a06n24.pdf>. Acesso em: 15 jul. 2015.

FREY, Klaus. Políticas Públicas: um debate conceitual e reflexões referentes à prática da análise de políticas públicas no Brasil. Planejamento e Políticas Públicas, n. 21, 2000. LOWI, Theodor. American Business, Public Policy, Case Studies and Political Theory. World Politics, n. 16, p. 677-715. 1964.

Four Systems of Policy, Politics, and choice. Public Administration Review, n. 32, p. 298-310, 1972.

MATTEI, Lauro. Impactos do Pronaf: análise dos indicadores. Brasília: Ministério do Desenvolvimento agrário, Núcleo de Estudos Agrários e Desenvolvimento Rural, 2005. Disponível em: <http://www.nead.gov.br>. Acesso em: 15 set. 2015. 
Programa Nacional de Fortalecimento da Agricultura Familiar (PRONAF): concepção, abrangência e limites observados. IV Encontro da Sociedade Brasileira de Sistemas de Produção. Belém, 2001. Disponível em: <http://gipaf.cnptia.embrapa.br/

publicacoes/artigos-e trabalhos/trabalhosbsp3.pdf/view>. Acesso em: 20 ago. 2015.

MDA. Ministério do Desenvolvimento Agrário. Programas. Disponível em:

<http://comunidades.mda.gov.br/portal/saf/programas/pronaf>. Acesso em: 18 ago. 2015.

OFFE, Claus. A democracia contra o Estado do bem-estar? Fundamentos estruturais das oportunidades políticas neoconservadoras. In: . Capitalismo desorganizado:

transformações contemporâneas do trabalho e da política. São Paulo: Brasiliense, 1981. p. 269-317.

SILVEIRA, D. C. et al. Políticas públicas e Welfare State: o plano nacional de microcrédito produtivo orientado (PNMPO) no Brasil. Revista Gesto. Edição Especial II CIGECO, Santo Ângelo, p. 84-95, 2015.

SOUZA, Celina. Elites ou lobbies: quem formula as políticas públicas brasileiras? RBCS, São Paulo, v. 16, n. 46, jun. 2001.

Políticas Públicas: uma revisão da literatura. Sociologias, Porto Alegre, ano 8, n. 16, jul./dez. 2006, p. 20-45. Disponível em: <http://www.scielo.br/pdf/soc/n16/a03n16.pdf>. Acesso em: 18 ago. 2015.

SOUZA, Marcelo Medeiros C. A transposição de teorias sobre a institucionalização do Welfare State para o caso dos países subdesenvolvidos. Rio de Janeiro, IPEA. Texto para Discussão n. 695, 1999. Disponível em: <http://repositorio.ipea.gov.br/bitstream/11058/ 2857/1/td_0695.pdf $>$. Acesso em: 18 ago. 2015.

Trajetória do Welfare State no Brasil: papel redistributivo das políticas sociais dos 1930 aos anos 1990. Texto para discussão n. 852, 2001. Brasília: IPEA, Disponível em: <http://www.ipea.gov.br/portal/images/stories/PDFs/TDs/td_0852.pdf>. Acesso em: 18 ago. 2015. 